Research Article

\title{
Poly(3-hydroxybutyrate-co-3-hydroxyvalerate) Production by Rhodospirillum rubrum Using a Two-Step Culture Strategy
}

\author{
Jie Liu, ${ }^{1,2}$ Youxi Zhao, ${ }^{1}$ Mengjie Diao, ${ }^{1}$ Wanqing Wang, ${ }^{1}$ Wei Hua, ${ }^{1}$ Shuang Wu, \\ Paul Chen, ${ }^{2}$ Roger Ruan, ${ }^{2}$ and Yanling Cheng $\mathbb{D}^{1,2}$ \\ ${ }^{1}$ Beijing Key Laboratory of Biomass Waste Resource Utilization, Biochemical Engineering College, Beijing Union University, \\ Beijing 100023, China \\ ${ }^{2}$ Center for Biorefining, and Department of Bioproducts and Biosystems Engineering, University of Minnesota, Saint Paul, \\ MN 55108, USA
}

Correspondence should be addressed to Yanling Cheng; cheng112@umn.edu

Received 15 April 2019; Accepted 13 June 2019; Published 4 August 2019

Academic Editor: Nenad Ignjatović

Copyright (C) 2019 Jie Liu et al. This is an open access article distributed under the Creative Commons Attribution License, which permits unrestricted use, distribution, and reproduction in any medium, provided the original work is properly cited.

\begin{abstract}
Polyhydroxyalkanoates (PHAs) are microbially synthesized biopolyesters which have attracted great attentions as a new biological material, potential alternative to traditional fossil fuel-based plastic due to their biodegradability and biocompatibility. Poly-3hydroxybutyrate (PHB) and poly-(3-hydroxybutyrate-co-3-hydroxyvalerate) (PHBV) are the most common members of PHAs. In this study, the nonsulfur and facultatively phototrophic bacterium Rhodospirillum rubrum was cultivated to accumulate PHA by a two-step culture strategy. Gas chromatography (GC), gas chromatography-mass spectrometry (GC-MS), and nuclear magnetic resonance spectroscopy (NMR) analyses showed that PHAs synthesized from fructose was PHBV, in which the $3 \mathrm{HV}$ content was $46.5 \mathrm{~mol} \%$, which means the better mechanical property. The molecular weight, distribution, and thermal features were characterized by gel permeation chromatography (GPC), differential scanning calorimeter (DSC), and thermo gravimetric analysis (TGA), respectively. The low PDI of 1.08 revealed the narrow and evenly molar mass distribution which shows the stable features. The high melting temperature and their other physical properties implied their potential applications. The traditional process of producing PHBV involves related carbon sources such as valeric acid. However, our study clearly described a new medium formula with fructose and a complete fermentation method to produce PHBV with a high $3 \mathrm{HV}$ faction and low molecular distribution.
\end{abstract}

\section{Introduction}

Polyhydroxyalkanoates (PHAs) are a group of microbially synthesized polyesters, which are formed and accumulated by bacteria under nutrient-limiting conditions (nitrogen or phosphorus) with excess carbon source; more than 300 different microorganisms have been identified to possess this ability; these bacteria can use these intracellular PHAs as carbon and energy reserves $[1,2]$. PHAs constitute for about $60-80 \%$ of the dry cell weight and can be identified by staining with Sudan Black B or using Nile blue A under fluorescent microscopy [3]. They have attracted great attentions as a new potential, biological materials alternative to traditional fossil plastic due to their good biological degradability, biocompatibility, and other special properties [4-6]. The physicochemical, thermal, and mechanical properties of PHAs are similar to some synthetic plastics, such as polypropylene (PP), polyethylene (PE), polyethylene terephthalate (PET), and low-density polyethylene (LDPE), and together with polylactic acid (PLA), polybutylene succinate (PBS), and poly propylene carbonate (PPC), they have been considered as sustainable, environment friendly, less petroleum dependent, and the green polymers for future applications $[7,8]$. Unlike the petroleum-based polymers, PHAs are completely biosynthesized and biodegradable. Therefore, PHAs has shown a more promising future in environmental concerns.

The physical properties of PHAs are determined by their molecular structure, molar masses, monomer composition, and distribution [9]. Over 150 different monomeric structures have been reported to diversify the material properties 
of PHAs, ranging from rigid plastics to elastic rubbers [10, 11]. Among them, the most common and intensively studied PHAs are poly-3-hydroxybutyrate (PHB) and copolymer poly-(3hydroxybutyrate-co-3-hydroxyvalerate) (PHBV) [12]. PHB has a high-degree crystallinity, which results in its poor physical properties such as stiffness, brittleness, and low mechanical strength. Furthermore, the high melting temperature makes it difficult to be manufactured. All these inherent deficiencies hinder the homopolymer applications. However, with the incorporation of 3-hydroxyvalerate (3HV) unit into the PHB crystal structure, the crystallization process not only slowed down markedly, and melting temperature began to decrease, but also provided better tensile strength to the polymer [13-15]. Therefore, PHBV, copolymer of 3-hydroxybutyrate (3HB) and 3-hydroxyvalerate $(3 \mathrm{HV})$, has more potential in biomedical and industrial applications than PHB. Additionally, it also demonstrates that the $3 \mathrm{HV}$ content plays a critical role in the physical properties of PHA polymers.

In the past decades, numerous research studies have engaged in PHAs production and many bacteria have been studied, such as Alcaligenes, Pseudomonas, Bacillus, Ralstonia, and some photosynthetic species [16]. However, most of them can naturally synthesize polyhydroxybutyrate (PHB), but only with precursor supplying (such as valeric acid) can produce a high content of other homopolyesters or copolymers (such as PHV and PHBV) instead of PHB. For example, Ralstonia eutropha $\mathrm{H} 16$ has served as a paradigm, which stores PHB up to $90 \%(w / w)$ of its cell dry weight $[17,18]$, while Lindenkamp with coauthors [19] cultured R. eutropha $\mathrm{H} 16$ on valerate as a sole carbon source that accumulated almost a PHV homopolyester with $99 \mathrm{~mol} \%$ $3 \mathrm{HV}$ constituents. Although more kinds of PHAs can be obtained by precursor supplying, the high cost will be another impediment to its development. Thus, a great deal of efforts should be devoted to find potential bacteria which can synthesize PHAs containing high HV fraction from unrelated carbon source. $R$. rubrum, a kind of purple nonsulfur and facultatively phototrophic bacterium, is known to produce up to $50 \%$ dry weight PHA [20]. As a PHA producer, it possesses many advantages over other bacteria. Firstly, it is one of the most versatile bacterial species in metabolism [21], which can grow in a broad range of anaerobic and aerobic conditions, autotrophically or heterotrophically, phototrophically or chemotrophically. Secondly, $R$. rubrum can produce PHAs composed of both short- and medium-chain-length monomers, while most bacteria just produce PHAs that are either short chain $\left(\mathrm{C}_{3}\right.$ to $\left.\mathrm{C}_{5}\right)$ or medium chain $\left(\mathrm{C}_{6}\right.$ to $\mathrm{C}_{14}$ ) [22]. Thirdly, it can use a variety of different carbon sources, even the toxic gas $\mathrm{CO}$ which is the major components of syngas [23]. Thus, $R$. rubrum has great promising to produce PHA, and its metabolic flexibility will offer all sorts of possibilities to synthesize PHBV containing a high $\mathrm{HV}$ fraction without the precursor supplying.

As PHA will be stored in cells under unfavorable growth conditions which indicates more time needed to get higher cell density. Hence, the two-step cultivation was preferred to accumulate PHBV by Rhodospirillum rubrum ATCC 11170
[24]. Firstly, the bacteria were cultured in growth medium so that a high cell density was achieved in a short time. Then, the cell was centrifuged and suspended in a mineral medium to synthesize PHBV. In the later medium, fructose is the sole carbon source and $\mathrm{NH}_{4} \mathrm{Cl}$ is the restricted nitrogen source.

\section{Materials and Methods}

2.1. Strain and Medium. R. rubrum (ATCC 11170) strain used in this study was obtained from the American Type Culture Collection (ATCC), cultured in an enriched broth medium (30 g of Trypticase soy broth per liter water) at $26^{\circ} \mathrm{C}$ and $170 \mathrm{rpm}$ aerobically in dark for 4 days, and the bacterium solution that started out colorless and transparent became red and opaque over time. The PHA production was assessed in $R$. rubrum cultured in fermentation medium containing excessive carbon source and deficient nitrogen source. In these experiments, the broth medium culture was collected by centrifugation at $4000 \mathrm{rpm}$ for $15 \mathrm{~min}$ at $4^{\circ} \mathrm{C}$, and then the cells were washed once with fermentation medium and resuspended in it. Cultures were shaken at $26^{\circ} \mathrm{C}$ and $170 \mathrm{rpm}$ in dark, but no strictly anaerobic growth.

A mineral medium (MM) was also used in this study, the composition of which medium was as follows (per liter of distilled water): $5.23 \mathrm{~g} \mathrm{NaH}{ }_{2} \mathrm{PO}_{4} \cdot 2 \mathrm{H}_{2} \mathrm{O}, 11.55 \mathrm{~g} \mathrm{Na}_{2} \mathrm{HPO}_{4}$ $\cdot 12 \mathrm{H}_{2} \mathrm{O}, 0.31 \mathrm{~g} \mathrm{~K}_{2} \mathrm{SO}_{4}, 0.04 \mathrm{~g} \mathrm{NaOH}, 0.1 \mathrm{~g} \mathrm{NH} \mathrm{NH}_{4}, 0.79 \mathrm{~g}$ $\mathrm{MgSO}_{4} \cdot 7 \mathrm{H}_{2} \mathrm{O}, 0.061 \mathrm{~g} \mathrm{CaCl} \cdot 2 \mathrm{H}_{2} \mathrm{O}$, and $1 \mathrm{~mL}$ trace metal solution $\left(0.048 \mathrm{~g} \mathrm{CuSO}_{4} \cdot 5 \mathrm{H}_{2} \mathrm{O}, 0.24 \mathrm{~g} \mathrm{ZnSO}_{4} \cdot 7 \mathrm{H}_{2} \mathrm{O}, 0.24 \mathrm{~g}\right.$ $\mathrm{MnSO}_{4}$ and $1.5 \mathrm{~g} \mathrm{FeSO}_{4} \cdot 7 \mathrm{H}_{2} \mathrm{O}$ per $100 \mathrm{ml}$ ), maintained $\mathrm{pH}$ around 7.0. It is worth noting that $\mathrm{NH}_{4} \mathrm{Cl}$, trace metal solution, $\mathrm{MgSO}_{4} \cdot 7 \mathrm{H}_{2} \mathrm{O}$, and $\mathrm{CaCl}_{2} \cdot 2 \mathrm{H}_{2} \mathrm{O}$ should be sterilized alone, and trace metal solution should be prepared when it will be used. Then add $10 \mathrm{~g}$ fructose as carbon source, the nitrogen source was $\mathrm{NH}_{4} \mathrm{Cl}$, and the carbon nitrogen ratio $(\mathrm{C} / \mathrm{N})$ was $154: 1$.

\subsection{PHA Extraction and Purification. Cells were harvested} from liquid cultures by centrifugation at $4000 \mathrm{rpm}$ for $15 \mathrm{~min}$, and the cell pellets were lyophilized and stored at $-80^{\circ} \mathrm{C}$ until analysis.

Dried cells were treated with hot chloroform solution at $100^{\circ} \mathrm{C}$ for at least $4 \mathrm{~h}$. The ratio of chloroform solution to dried cells was $15: 1(\mathrm{v} / \mathrm{w})$. After cooling to room temperature, equal volume of water was added and mixed evenly. After centrifugation at $5000 \mathrm{rpm}$ for $5 \mathrm{~min}$, filter the organic phase by filtration in order to remove of cell debris and obtain clarified the organic phase, followed by precipitation with 10 volume of prechilled ethanol. Precipitation was collected by centrifugation at $5000 \mathrm{rpm}$ for $30 \mathrm{~min}$. To obtain a pure product, the precipitate was redissolved in chloroform and the process was repeated. The collected PHA was dried in an oven to remove all residual solvent [25].

2.3. GC and GC-MS Analysis. PHAs concentration and composition were determined using $80 \mathrm{mg}$ dry cell samples and analyzed by gas chromatography (GC). At first, dried cells were subjected to derivatization in a mixture of $2 \mathrm{~mL}$ esterified liquid $(1 \mathrm{~g} / \mathrm{L}$ sodium benzoate was used as an 
internal standard and dissolved in $97 \%(\mathrm{v} / \mathrm{v})$ methanol and $3 \%(\mathrm{v} / \mathrm{v})$ concentrated sulfuric acid) and $2 \mathrm{~mL}$ chloroform solution at $100^{\circ} \mathrm{C}$ for $4 \mathrm{~h}$. Then, the resulting sample $(1 \mu \mathrm{L})$ methanolyzed was assayed using GC Clarus 580 (PerkinElmer, USA) equipped with a BD-FFAP column $(30 \mathrm{~m} \times 0.32 \mathrm{~nm} \times 0.25 \mu \mathrm{m})$ [26]. Nitrogen was separation carrier gas $(2 \mathrm{~mL} / \mathrm{min})$. The oven temperature was programmed at an initial temperature of $80^{\circ} \mathrm{C}$ for $1.5 \mathrm{~min}$ and subsequently raised at $30^{\circ} \mathrm{C} / \mathrm{min}$ to $140^{\circ} \mathrm{C}$ and $40^{\circ} \mathrm{C} / \mathrm{min}$ to $220^{\circ} \mathrm{C}$ and held for $0.5 \mathrm{~min}$. The temperatures of the injector and detector were 200 and $220^{\circ} \mathrm{C}$, respectively [27].

The purified PHAs sample was prepared with the same derivatization method as mentioned above, but water was used to remove sulfuric acid. A $1 \mu \mathrm{L}$ portion of methyl esters was injected into a GC-MS (Agilent 7890B/7693, HP-5MS column $(30 \mathrm{~m} \times 0.25 \mathrm{~mm} \times 0.25 \mu \mathrm{m}))$ to determine the composition of the produced polymer [28]. The temperature of the injection port, interface, quadrupole, and ion source was set at 250, 280, 130 , and $250^{\circ} \mathrm{C}$, respectively. The temperature gradient was programmed as described by Tan and coauthors [29].

2.4. NMR Analysis. ${ }^{1} \mathrm{H}-\mathrm{NMR}$ analysis is an important means to detect the chemical structure of PHAs. The monomer compositions of PHAs copolymers were investigated using a Bruker AVANCE III $400 \mathrm{MHz}$ NMR spectrometer (Bruker, Germany). The detailed procedure was according to that mentioned by Han and coauthors [30], which is described as follows: $10 \mathrm{mg}$ purified PHA was dissolved in $1 \mathrm{~mL}$ deuterated chloroform or just at a concentration of $10 \mathrm{mg} / \mathrm{mL}$. Tetramethylsilane (TMS) was used as the internal standard, and the $400 \mathrm{MHz}{ }^{1} \mathrm{H}-\mathrm{NMR}$ spectra were recorded at $25^{\circ} \mathrm{C}$.

2.5. Determination of the Molecular Weight. Gel permeation chromatography (GPC) analyses were carried out using a pump (Shimadzu LC-10AD VP), detector (Shimadzu RID10A), and Shodex GPC Chirfm $4 \times 10^{5}$ and $4 \times 10^{6}$ Mixed Bed column $(300 \times 8 \mathrm{~mm})$. It can estimate the average molecular weight and molecular weight distribution of PHAs. Analyses were performed at $35^{\circ} \mathrm{C}$ using chloroform as a mobile phase at a flow rate of $1 \mathrm{~mL} / \mathrm{min}$. The instrument was calibrated with polystyrene narrow standards and then constructed a calibration curve [31].

2.6. Measurement of Thermodynamic Properties. Differential scanning calorimetry (DSC) and thermogravimetric analysis (TGA) are the two most common methods. DSC and TGA were performed with DTG-60A Instrument (Shimadzu, Japan), and the scanning temperature was from $50^{\circ} \mathrm{C}$ to $500^{\circ} \mathrm{C}$. The empirical method for DSC refers to Cibichakravarthy et al. [32]. The cool crystallization temperature $\left(T_{c}\right)$ and melting temperature $\left(T_{m}\right)$ were taken at summit of crystal peak and summit of melting peak in the second heating run, respectively.

The thermal cyclization and the thermal stabilities of PHA were analyzed by TGA, and the detail processes are as follows [33]: $14.6712 \mathrm{mg}$ PHAs samples were heated at $10^{\circ} \mathrm{C} / \mathrm{min}$ from $50^{\circ} \mathrm{C}$ to $500^{\circ} \mathrm{C}$ in a nitrogen atmosphere at a flow rate of $50 \mathrm{~mL} / \mathrm{min}$.

\section{Results and Discussion}

3.1. PHA Accumulation and Preliminary Identification. $R$. rubrum was cultured in enriched broth medium and mineral medium (MM) by the two-step method described above. PHAs were extracted and detected according to the method described above. 3-hydroxybutyrate acid and 3hydroxypentanoic acid were used as positive controls. The values of the peak areas were determined according to their retention time. According to the retention time, it can be preliminarily determined that the PHAs accumulated by $R$. rubrum in this study contained $3 \mathrm{HB}$ and $3 \mathrm{HV}$, which indicated that PHBV was accumulated successfully by $R$. rubrum.

3.2. Structure Analysis of the PHA. To further confirm the structure of the PHAs, GC-MS, and NMR were used to determine the structure of the PHBV. We used water and chloroform to extract and purify PHA, and then methyl ester of purified PHAs was prepared for GC-MS analysis to determine the monomer composition of it. Two chromatogram peaks with a retention time of 4.201 and $5.636 \mathrm{~min}$ were compared with the data from the mass spectrum library. The contrast results showed that the two peaks matched that of methyl esters of 3-hydroxybutyrate (3HB) and 3-hydroxyvalerate 3HV (Figure 1). This can be concluded that the material was PHAs; moreover, it was composed of $3 \mathrm{HB}$ and $3 \mathrm{HV}$ monomers, and the species of PHAs was PHBV.

In the process of water extraction, $3 \mathrm{HB}$ methyl ester and $3 \mathrm{HV}$ methyl ester were damaged to varying degrees. Therefore, the GC-MS method cannot accurately determine the monomer ratio of $3 \mathrm{HB}$ and $3 \mathrm{HV}$, so we use the NMR hydrogen spectrum scanning to further determine it. In the spectrum, each peak corresponds to a certain carbon atom in monomers, and two proton peaks of the $\mathrm{CH}$ group at 5.10-5.20 and 5.21-5.30 ppm belonged to $3 \mathrm{HV}$ and $3 \mathrm{HB}$, respectively (Figure 2). The result of ${ }^{1} \mathrm{H}$ NMR analysis showed that the copolymers were PHBV, which is in full agreement with the results of GC-MS analysis. The peak area of $3 \mathrm{HB}$ was set as the standard of 1.0 , and the ratio of the area of $3 \mathrm{HV}$ was 0.87 . The content of $3 \mathrm{HV}$ can be calculated as follows: $3 \mathrm{HV}$ content $(\mathrm{mol} \%)$ $=$ area of $\mathrm{V}_{3} /\left(\right.$ area of $\mathrm{B}_{3}+$ area of $\left.\mathrm{V}_{3}\right) \times 100 \%$. It was calculated that the mole fraction of $3 \mathrm{HV}$ was $46.5 \%$. Taking on Zhao et al. [28], they found a novel PHBV-accumulating species Halogranum amylolyticum TNN58 synthesizing a PHBV containing $20 \mathrm{~mol} \% 3 \mathrm{HV}$ fraction. Obviously, our result was significant in producing $\mathrm{PHBV}$ with high $\mathrm{HV}$ content with no genetic/metabolic engineering or precursor supplying so far, which is the highest $3 \mathrm{HV}$ content in PHBV accumulated by R. rubrum.

The two-step culture method has been implemented in previous publications to produce PHA by R. rubrum, and the RRNCO medium was used in those studies [34]. The main 


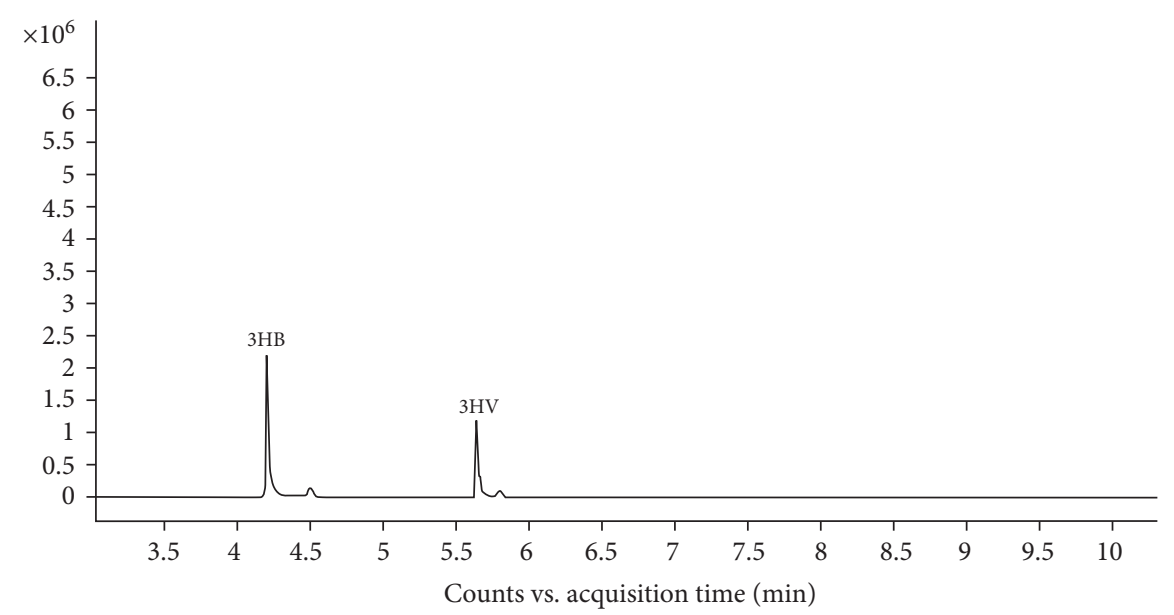

(a)

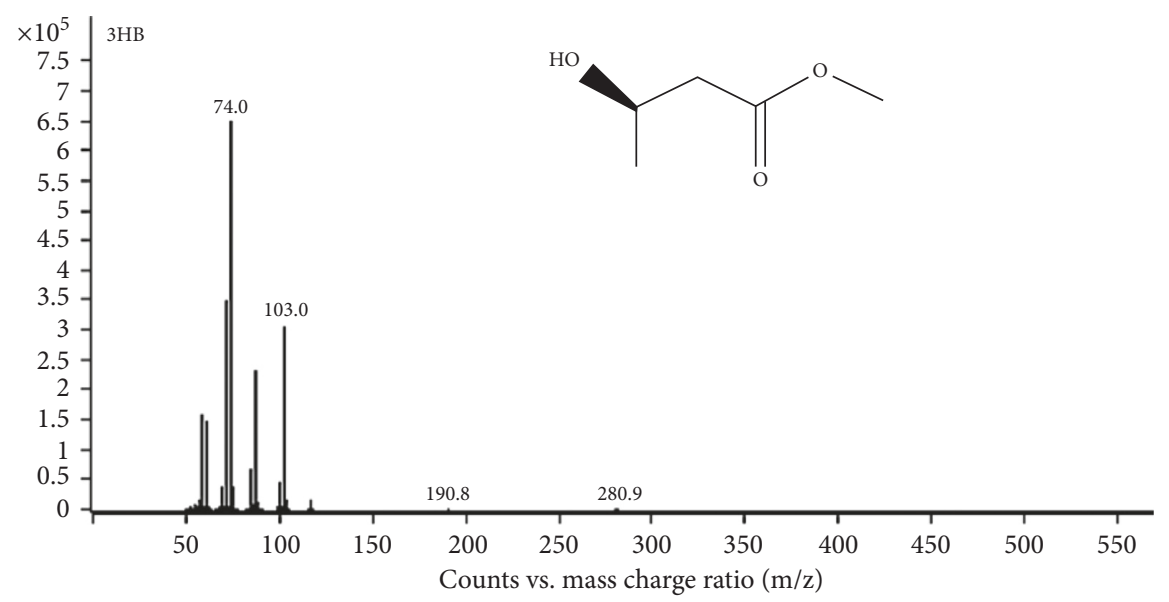

(b)

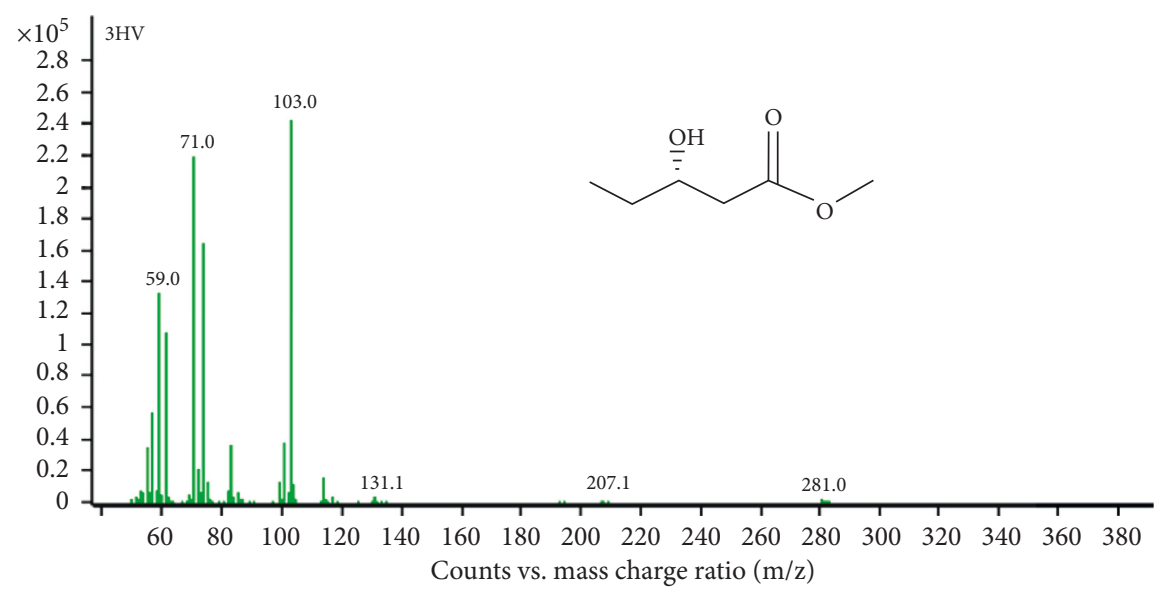

(c)

Figure 1: Composition analysis of purified PHA-extracted material from R. rubrum (ATCC 11170) by GC-MS.

carbon source in the RRNCO medium was sodium acetate, the nitrogen source was yeast extract and $\mathrm{NH}_{4} \mathrm{Cl}$, and the carbon source was in small amount. The cultures were shaken under $5000 \mathrm{~lx}$ light intensity and strictly anaerobic conditions. As a result, $\mathrm{PHBV}$ in which the $3 \mathrm{HV}$ content was only $0.7 \%$ was obtained [20]. In contrast, in the study, fructose was used as the sole carbon source, the carbon nitrogen ratio $(\mathrm{C} / \mathrm{N})$ was $154: 1$, and the $3 \mathrm{HV}$ content was up to $46.5 \%$. Therefore, the carbon sources and the $\mathrm{C} / \mathrm{N}$ ratio may be important factors affecting the content of $3 \mathrm{HV}$. The higher the $\mathrm{C} / \mathrm{N}$ ratio, the more unbalanced the growth environment, which is more beneficial for the accumulation of PHBV with high $\mathrm{HV}$ content. Furthermore, the constituent of RRNCO was more complex. Biotin, chelated iron- 


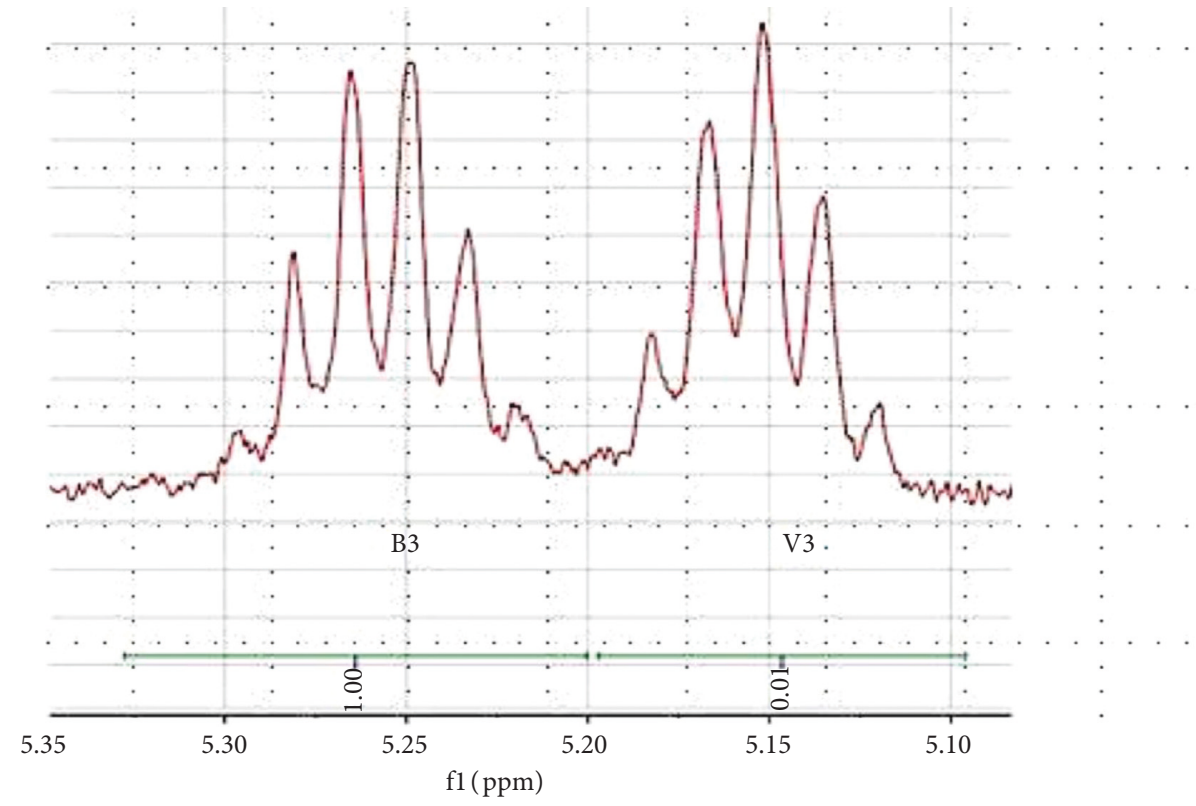

Figure 2: The monomer compositions analysis of purified PHA-extracted material from $R$. rubrum (ATCC 11170) by ${ }^{1} \mathrm{H}-\mathrm{NMR}$.

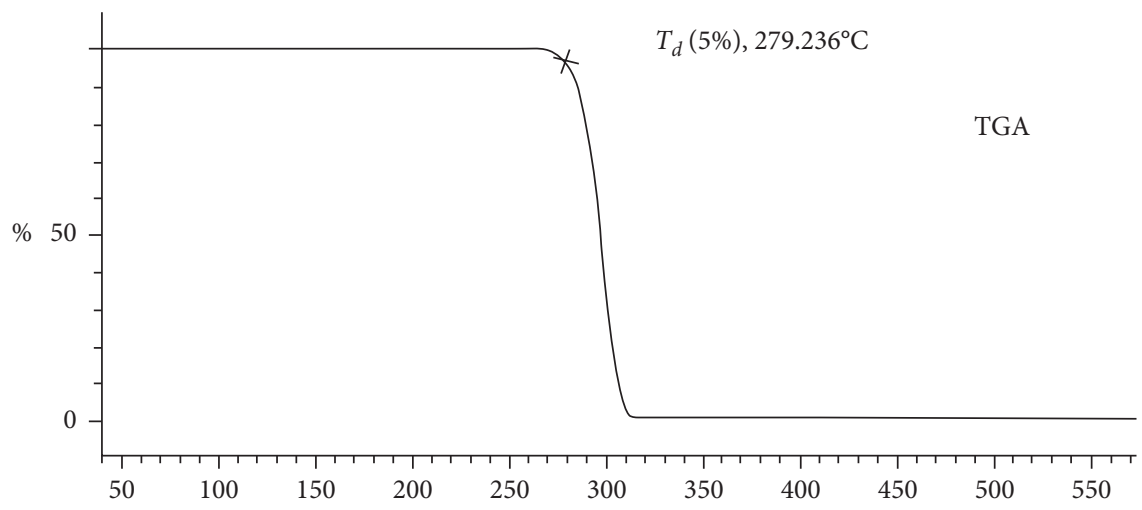

(a)

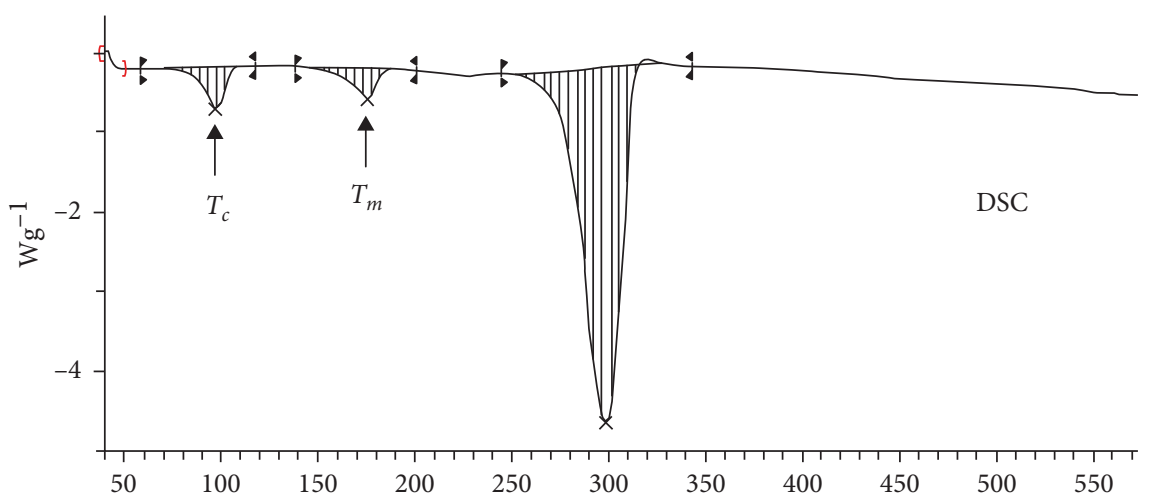

(b)

FIgURE 3: TGA and DSC thermographs of purified PHBV extracted material from R. rubrum (ATCC 11170).

molybdenum solution, $\mathrm{NiCl}_{2}$, and MOPS in RRNCO were not needed in the medium, and the common inorganic salt solution was enough. Additionally, it is not necessary to have light and to be strictly anaerobic. All of these showed that the method cannot only produce high content of $3 \mathrm{HV}$, but also save energy and operate conveniently.
3.3. Physical Properties of $P H B V$. The physical properties of polymers are characterized by thermodynamic parameters, molecular weight distribution, and mechanical properties. In this study, the properties of $\mathrm{PHBV}$ were investigated by TGA and DSC analyses described above (Figure 3 ) and are summarized in Table 1. Among all the 
TABLE 1: Thermal properties of PHBV.

\begin{tabular}{lccc}
\hline Sample & & Thermal properties \\
& $T_{c}^{\mathrm{a}}\left({ }^{\circ} \mathrm{C}\right)$ & $T_{m}^{\mathrm{a}}\left({ }^{\circ} \mathrm{C}\right)$ & $T_{d}^{\mathrm{b}}\left({ }^{\circ} \mathrm{C}\right)$ \\
\hline PHBV & 96.15 & 173.56 & 279.24 \\
\hline
\end{tabular}

${ }^{\mathrm{a}}$ Determined from the DSC second heating run. ${ }^{\mathrm{b}}$ Determined from the TGA at the beginning of $5 \%$ degradation.

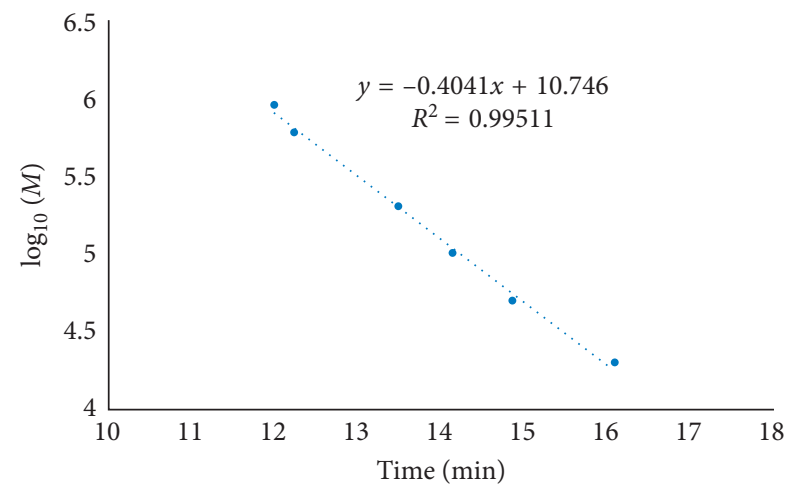

(a)

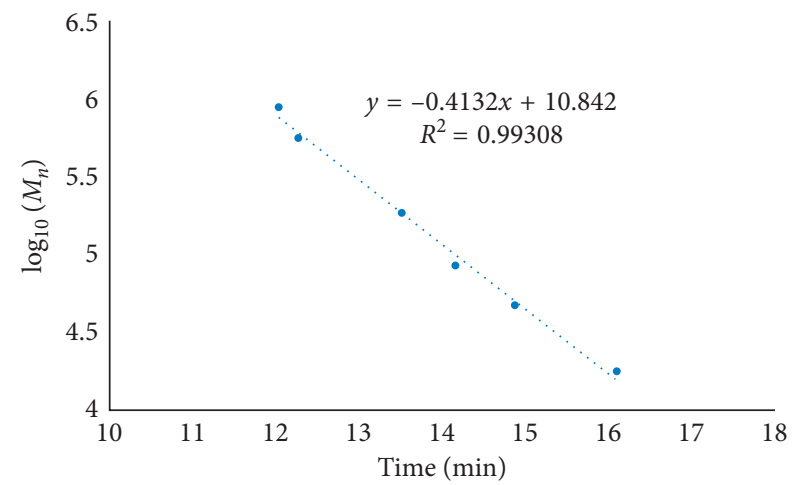

(b)

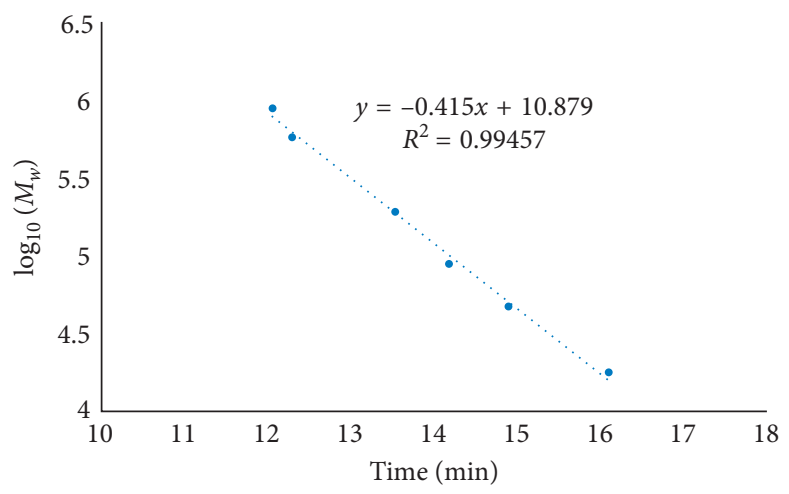

(c)

Figure 4: (a) Standard curve of molecular weight of polystyrene; (b) Standard curve of number-average molar mass $\left(M_{n}\right)$ of polystyrene; (c) Standard curve of weight-average molar mass $\left(M_{w}\right)$ of polystyrene.

thermal properties, the thermal stability is particularly important. PHAs with low melting temperatures and/or increased thermal stability are desirable. The thermal stability of the material was evaluated and measured by the degradation temperature $\left(T_{d}\right)$ corresponding to the mass loss of $5 \%$. As shown in Figure 4 , the $T_{d}, T_{c}$, and $T_{m}$ of the PHBV in this study was $279.236^{\circ} \mathrm{C}, 96.150^{\circ} \mathrm{C}$, and $173.560^{\circ} \mathrm{C}$, respectively. As reported, $\mathrm{PHB}$ was thermally unstable and possibly degradable when submitted to usual process conditions. Its $T_{d}$ was about $220^{\circ} \mathrm{C}$ which was near its melting point (about $180^{\circ} \mathrm{C}$ ) $[35,36]$. Compared with $\mathrm{PHB}$, the PHBV obtained in the study had a higher $T_{d}\left(279.236^{\circ} \mathrm{C}\right)$, which was far apart from its melting temperature $T_{m}$. This showed that it had better thermal stability and was not easy to be degraded in the process of processing. Also, the lower $T_{m}$ implied the possibility of being processed at a lower temperature. This material had better prospect applications. And, the
$T_{c}$ was a little higher than other reported materials. The higher $T_{c}$ meant it needed more time to be crystallized completely. According to this point, the crystallinity percentages of our PHBV might be a little higher, and this enhanced the strength of our material, as the crystallization of $\mathrm{PHB}$ was not easily disturbed by $3 \mathrm{HV}$ monomers. Therefore, the reason of the high crystallinity percentages might be some short segments of PHB in this polymer.

GPC is widely used to measure the average molecular weight and molar mass distribution of PHBV. In this research, it was mixed with the polystyrene with molecular weights of $20 \mathrm{~K}, 50 \mathrm{~K}, 100 \mathrm{~K}, 200 \mathrm{~K}, 600 \mathrm{~K}$, and $900 \mathrm{~K}$. The retention time was measured by GPC, and the standard curve was obtained (Figure 4) (retention time as the abscissa, $\log _{10} M, \log _{10} M_{n}, \log _{10} M_{w}$ as the ordinate). Then, we measured our PHBV sample and obtained its retention time $(12.4625 \mathrm{~min})$. The molecular weight, the 
TABLE 2: Molar masses and mechanical properties of $\mathrm{PHBV}$ polymers.

\begin{tabular}{lcccc}
\hline Sample & $M\left(10^{5}\right)$ & $M_{n}\left(10^{5}\right)$ & $M_{w}\left(10^{5}\right)$ & PDI $\left(M_{w} / M_{n}\right)$ \\
\hline PHBV & 5.13 & 4.93 & 5.31 & 1.08 \\
\hline
\end{tabular}

number-average molar mass $\left(M_{n}\right)$, and the weight-average molar mass $\left(M_{w}\right)$ were calculated and filled in Table 2. The low PDI of 1.08 reflected that the molar mass distribution of our material was narrow and even. The result was lower than the PDI of PHBV biosynthesized by other known microorganisms [37-39].

\section{Conclusions}

In this study, fructose was the sole carbon source in the fermentation medium for PHBV accumulation, and experiments were performed by a two-step batch strategy. The results showed that the PHA accumulated in the study was PHBV, which consisted of some short segments of PHB and PHV linked together. The content of $3 \mathrm{HV}$ in the PHBV was $46.5 \%$, which was much higher than that mentioned in previous reports. The physical properties such as molar masses and thermal properties of the PHBV were tested. The PDI was lower than those biosynthesized by other known microorganisms, which means the molar mass distribution of our material was narrow and even. The $T_{d}$ and $T_{m}$ were $279.236^{\circ} \mathrm{C}$ and $173.560^{\circ} \mathrm{C}$, respectively, which implied that it possessed good thermal stability and was not easy to be degraded in processing. The higher $T_{c}$ means higher crystallinity percentages of PHBV, it was supposed that there were some short segments of PHB in the polymer chains. Therefore, it was easy to synthesize PHBV block copolymers, and its strength would be enhanced as well. In summary, the PHBV produced by $R$. rubrum through the designed medium and method showed wide potential applications.

\section{Data Availability}

The data used to support the findings of this study are available from the corresponding author upon request.

\section{Conflicts of Interest}

The authors declare that they have no conflicts of interest.

\section{Acknowledgments}

This program was supported by Beijing Union University (Grant nos. BPHR2017CZ02 and KYDE40201704); Ministry of Science and Technology, China, "863 Plan" (Grant nos. 2015AA020202 and 2014AA022002); International Scientific and Technological Cooperation Program of China (Grant nos. 2015DFA60170 and 2014DFA61040); Beijing Municipal Education Commission (Grant no. KM201511417011); and General Project of Science and Technology Program of Beijing Education Committee (Grant no. 22139916080101-010).

\section{References}

[1] D. Jendrossek and D. Pfeiffer, "New insights in the formation of polyhydroxyalkanoate granules (carbonosomes) and novel functions of poly(3-hydroxybutyrate)," Environmental Microbiology, vol. 16, no. 8, pp. 2357-2373, 2014.

[2] C. Kourmentza and M. Kornaros, "Biotransformation of volatile fatty acids to polyhydroxyalkanoates by employing mixed microbial consortia: the effect of $\mathrm{pH}$ and carbon source," Bioresource Technology, vol. 222, pp. 388-398, 2016.

[3] J. Aravind and H. S. Sangeetha, "A study on effect of mutagenic agents on Polyhydroxyalkanoates (PHA) production," Journal of Microbiology Biotechnology \& Food, vol. 4, no. 3, pp. 384-386, 2016.

[4] T. A. Hottle, M. M. Bilec, and A. E. Landis, "Sustainability assessments of bio-based polymers," Polymer Degradation and Stability, vol. 98, no. 9, pp. 1898-1907, 2013.

[5] X. Gao, J.-C. Chen, Q. Wu, and G.-Q. Chen, "Polyhydroxyalkanoates as a source of chemicals, polymers, and biofuels," Current Opinion in Biotechnology, vol. 22, no. 6, pp. 768-774, 2011, in Chinese.

[6] D.-C. Meng, R. Shen, H. Yao, J.-C. Chen, Q. Wu, and G.-Q. Chen, "Engineering the diversity of polyesters," Current Opinion in Biotechnology, vol. 29, no. 1, pp. 24-33, 2014, in Chinese.

[7] G.-Q. Chen and M. K. Patel, "Plastics derived from biological sources: present and future: a technical and environmental review," Chemical Reviews, vol. 112, no. 4, pp. 2082-2099, 2012, in Chinese.

[8] G. Q. D. Chen, Plastics from Bacteria: Natural Functions and Applications, vol. 48, pp. 124-137, Springer Ebooks, Berlin, Germany, 2010, in Chinese.

[9] E. N. Pederson, C. W. J. McChalicher, and F. Srienc, "Bacterial synthesis of PHA block copolymers," Biomacromolecules, vol. 7, no. 6, pp. 1904-1911, 2006.

[10] G.-Q. Chen and Q. Wu, "Microbial production and applications of chiral hydroxyalkanoates," Applied Microbiology and Biotechnology, vol. 67, no. 5, pp. 592-599, 2005, in Chinese.

[11] A. Steinbüchel and H. E. Valentin, "Diversity of bacterial polyhydroxyalkanoic acids," FEMS Microbiology Letters, vol. 128, no. 3, pp. 219-228, 1995.

[12] I. Noda, P. R. Green, M. M. Satkowski, and L. A. Schechtman, "Preparation and properties of a novel class of polyhydroxyalkanoate copolymers," Biomacromolecules, vol. 6, no. 2, pp. 580-586, 2005.

[13] I. S. Sankhla, R. Bhati, A. K. Singh, and N. Mallick, "Poly(3hydroxybutyrate-co-3-hydroxyvalerate) co-polymer production from a local isolate, Brevibacillus invocatus MTCC 9039," Bioresource Technology, vol. 101, no. 6, pp. 1947-1953, 2010.

[14] J. Ahn, E. H. Jho, M. Kim, and K. Nam, "Increased 3HV concentration in the bacterial production of 3-hydroxybutyrate $(3 \mathrm{HB})$ and 3-hydroxyvalerate $(3 \mathrm{HV})$ copolymer with acid-digested rice straw waste," Journal of Polymers and the Environment, vol. 24, no. 2, pp. 98-103, 2016.

[15] Q. S. Liu, H. X. Zhang, B. Y. Deng, and X. Y. Zhao, "Poly(3hydroxybutyrate) and poly(3-hydroxybutyrate-co-3-hydroxyvalerate): structure, property, and fiber," International Journal of Polymer Science, vol. 2014, Article ID 374368, 11 pages, 2014.

[16] K. Sangkharak and P. Prasertsan, "Screening and identification of polyhydroxyalkanoates producing bacteria and biochemical characterization of their possible application," The Journal of General and Applied Microbiology, vol. 58, no. 3, pp. 173-182, 2012.

[17] M. Beeby, M. Cho, J. Stubbe, and G. J. Jensen, "Growth and localization of polyhydroxybutyrate granules in Ralstonia 
eutropha," Journal of Bacteriology, vol. 194, no. 5, pp. 1092-1099, 2012.

[18] S. L. Riedel, S. Jahns, S. Koenig et al., "Polyhydroxyalkanoates production with Ralstonia eutropha from low quality waste animal fats," Journal of Biotechnology, vol. 214, pp. 119-127, 2015.

[19] N. Lindenkamp, E. Volodina, and A. Steinbüchel, “Genetically modified strains of Ralstonia eutropha H16 with $\beta$-ketothiolase gene deletions for production of copolyesters with defined 3-hydroxyvaleric acid contents," Applied and Environmental Microbiology, vol. 78, no. 15, pp. 5375-5383, 2012.

[20] H. Jin and B. J. Nikolau, "Role of genetic redundancy in polyhydroxyalkanoate (PHA) polymerases in PHA biosynthesis in Rhodospirillum rubrum," Journal of Bacteriology, vol. 194, no. 20, pp. 5522-5529, 2012.

[21] O. Revelles, I. Calvillo, A. Prieto, and M. A. Prieto, "Syngas fermentation for polyhydroxyalkanoate production in Rhodospirillum rubrum," in Hydrocarbon and Lipid Microbiology Protocols, T. McGenity, K. Timmis, and B. Nogales, Eds., pp. 105-119, Springer, Berlin, Germany, 2016.

[22] H. Brandl Jr, E. J. Knee, R. C. Fuller, R. A. Gross, and R. W. Lenz, "Ability of the phototrophic bacterium Rhodospirillum rubrum to produce various poly ( $\beta$-hydroxyalkanoates): potential sources for biodegradable polyesters," International Journal of Biological Macromolecules, vol. 11, no. 1, pp. 49-55, 1989.

[23] D. Heinrich, M. Raberg, P. Fricke et al., "Synthesis gas (Syngas)-Derived medium-chain-length polyhydroxyalkanoate synthesis in engineered Rhodospirillum rubrum," Applied and Environmental Microbiology, vol. 82, no. 20, pp. 6132-6140, 2016.

[24] C. Kourmentza, J. Plácido, N. Venetsaneas et al., "Recent advances and challenges towards sustainable polyhydroxyalkanoate (PHA) production," Bioengineering, vol. 4, no. 2, p. 55, 2017.

[25] J. Han, M. Li, J. Hou, L. Wu, J. Zhou, and H. Xiang, "Comparison of four phaC genes from Haloferax mediterranei and their function in different PHBV copolymer biosyntheses in Haloarcula hispanica," Saline Systems, vol. 6, no. 1, pp. 1-9, 2010, in Chinese.

[26] Y. Zhao, Z. Rao, Y. Xue, P. Gong, Y. Ji, and Y. Ma, "Biosynthesis, property comparison, and hemocompatibility of bacterial and haloarchaeal poly(3-hydroxybutyrate-co-3hydroxyvalerate)," Science Bulletin, vol. 60, no. 22, pp. 19011910, 2015, in Chinese.

[27] Y. X. Zhao, Biosynthesis of PHBV with Haloarchaeon Halogranum Amylolyticum TNN58, Jiangnan University, Jiangsu, China, 2015, in Chinese.

[28] Y.-X. Zhao, Z.-M. Rao, Y.-F. Xue, P. Gong, Y.-Z. Ji, and Y.-H. Ma, "Poly(3-hydroxybutyrate-co-3-hydroxyvalerate) production by haloarchaeon Halogranum amylolyticum," Applied Microbiology and Biotechnology, vol. 99, no. 18, pp. 7639-7649, 2015, in Chinese.

[29] G.-Y. A. Tan, C.-L. Chen, L. Ge et al., "Enhanced gas chromatography-mass spectrometry method for bacterial polyhydroxyalkanoates analysis," Journal of Bioscience and Bioengineering, vol. 117, no. 3, pp. 379-382, 2014, in Chinese.

[30] J. Han, L.-P. Wu, J. Hou, D. Zhao, and H. Xiang, "Biosynthesis, characterization, and hemostasis potential of tailormade poly(3-hydroxybutyrate-co-3-hydroxyvalerate) produced by Haloferax mediterranei," Biomacromolecules, vol. 16, no. 2 , pp. $578-588,2015$, in Chinese.

[31] I. Kwiecień, I. Radecka, M. Kwiecień, and G. Adamus, "Synthesis and structural characterization of bioactive PHA and $\gamma$-PGA oligomers for potential applications as a delivery system," Materials, vol. 9, no. 5, pp. 307-319, 2016.

[32] B. Cibichakravarthy, S. Abinaya, and S. R. Prabagaran, "Syntrophic association of termite gut bacterial symbionts with bifunctional characteristics of cellulose degrading and polyhydroxyalkanoate producing bacteria," International Journal of Biological Macromolecules, vol. 103, pp. 613-620, 2017.

[33] J. Asrar, H. E. Valentin, P. A. Berger, M. Tran, S. R. Padgette, and J. R. Garbow, "Biosynthesis and properties of poly(3hydroxybutyrate-co-3-hydroxyhexanoate) polymers," Biomacromolecules, vol. 3, no. 5, pp. 1006-1012, 2002.

[34] R. L. Kerby, P. W. Ludden, and G. P. Roberts, "Carbon monoxide-dependent growth of Rhodospirillum rubrum," Journal of Bacteriology, vol. 177, no. 8, pp. 2241-2244, 1995.

[35] S. Pradhan, A. J. Borah, M. K. Poddar, P. K. Dikshit, L. Rohidas, and V. S. Moholkar, "Microbial production, ultrasound-assisted extraction and characterization of biopolymer polyhydroxybutyrate (PHB) from terrestrial $(P$. hysterophorus) and aquatic (E. crassipes) invasive weeds," Bioresource Technology, vol. 242, pp. 304-310, 2017.

[36] N. G. Jaques, I. D. D. S. Silva, M. D. C. B. Neto, R. K. M. Diniz, R. M. R. Wellen, and E. L. Canedo, "Comparative study of the effect of $\mathrm{TiO}_{2}$ and $\mathrm{ZnO}$ on the crystallization of $\mathrm{PHB}$," Matéria, vol. 22, no. 4, 2017.

[37] M. Koller, P. Hesse, R. Bona, C. Kutschera, A. Atlić, and G. Braunegg, "Potential of various archae- and eubacterial strains as industrial polyhydroxyalkanoate producers from whey," Macromolecular Bioscience, vol. 7, no. 2, pp. 218-226, 2007.

[38] G. Sathiyanarayanan, S. K. Bhatia, H.-S. Song et al., "Production and characterization of medium-chain-length polyhydroxyalkanoate copolymer from Arctic psychrotrophic bacterium Pseudomonas sp. PAMC 28620," International Journal of Biological Macromolecules, vol. 97, pp. 710-720, 2017.

[39] S. Tomizawa, J.-A. Chuah, K. Matsumoto, Y. Doi, and K. Numata, "Understanding the limitations in the biosynthesis of polyhydroxyalkanoate (PHA) from lignin derivatives," ACS Sustainable Chemistry \& Engineering, vol. 2, no. 5, pp. 1106-1113, 2014. 

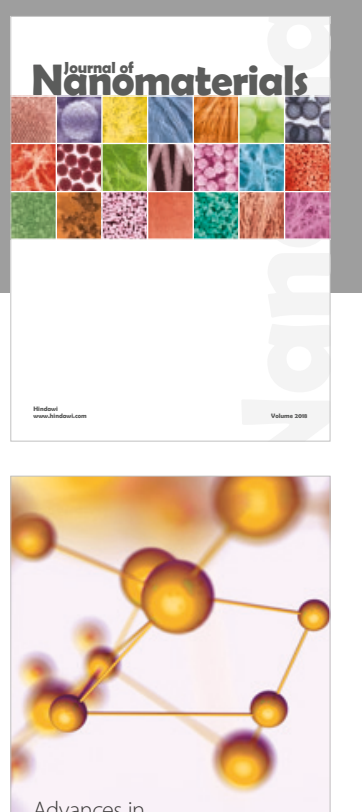

Physical Chemistry
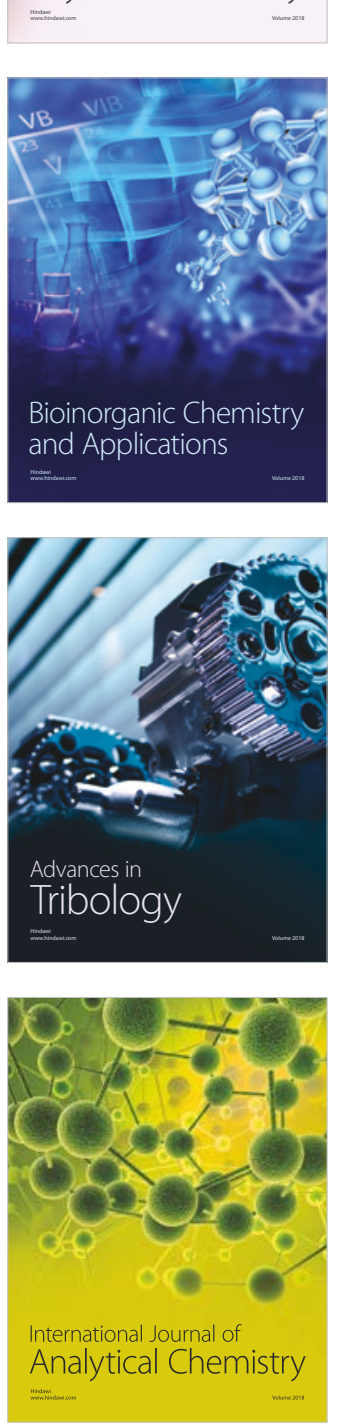

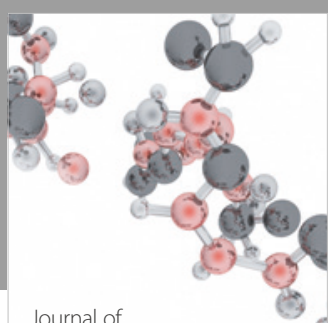

Analytical Methods

in Chemistry

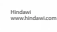

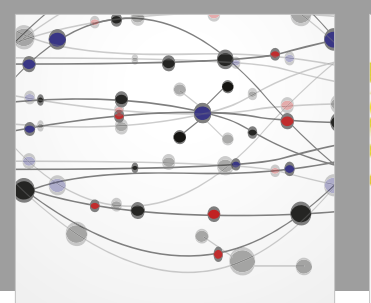

The Scientific World Journal

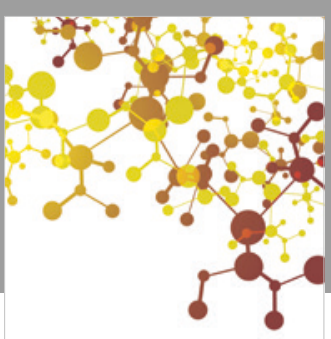

Journal of

Applied Chemistry
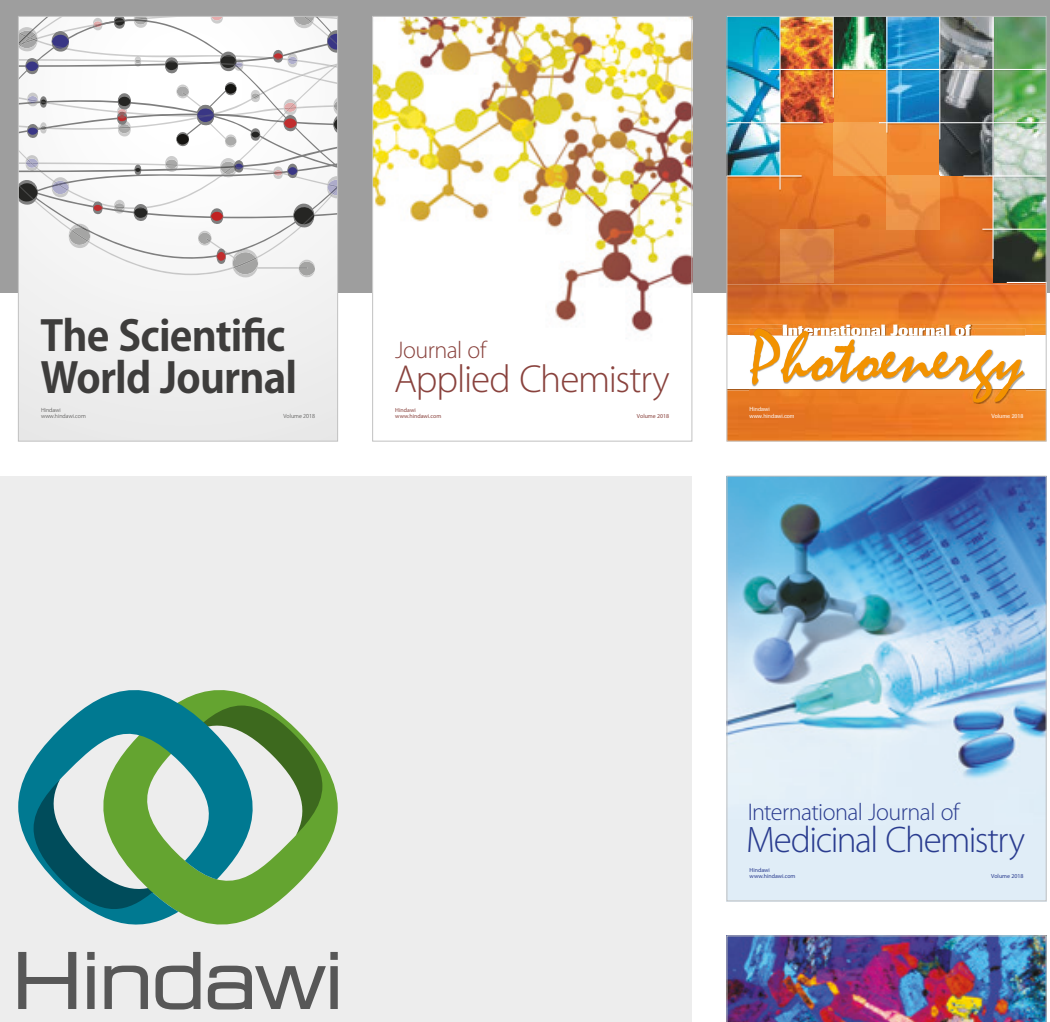

Submit your manuscripts at

www.hindawi.com
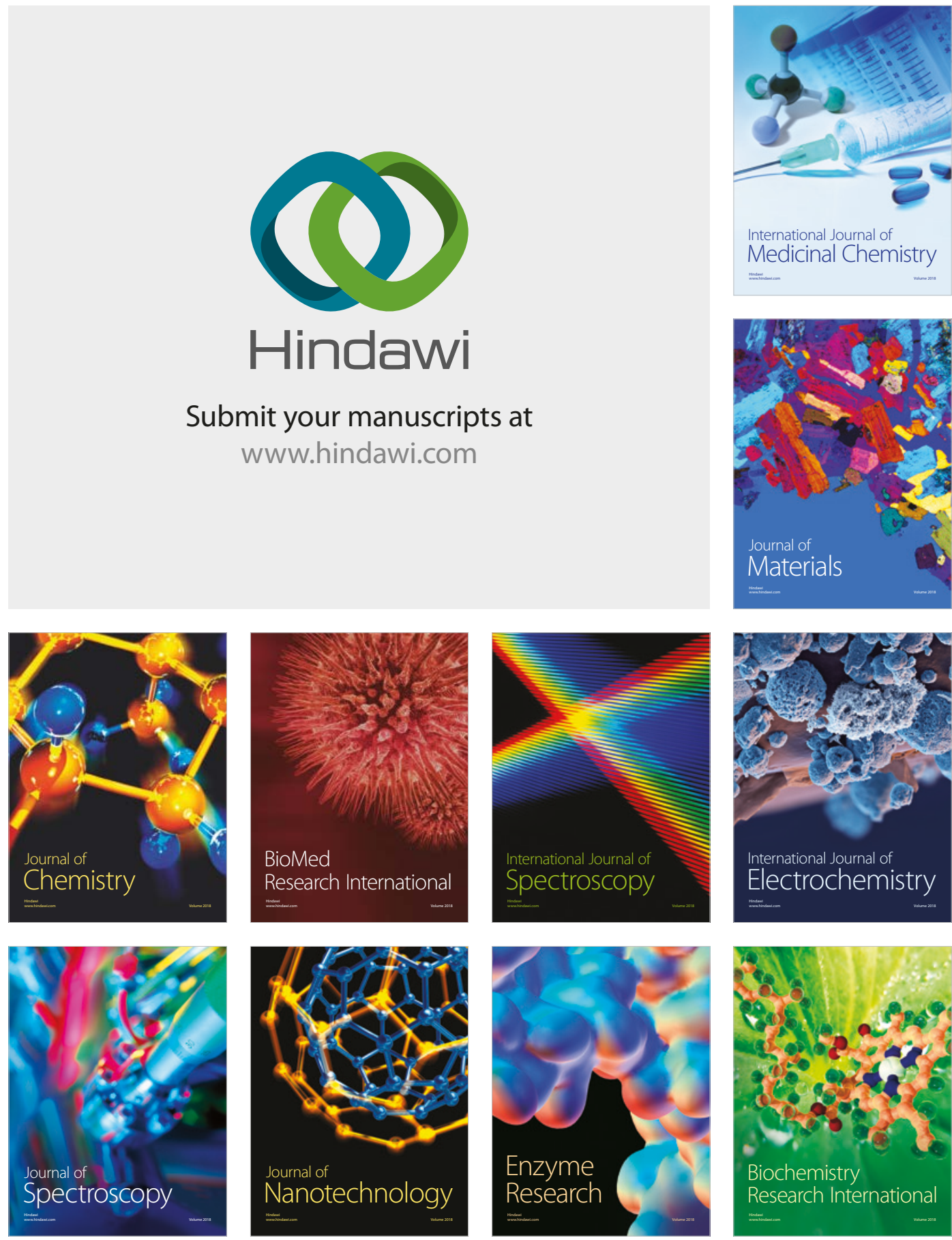
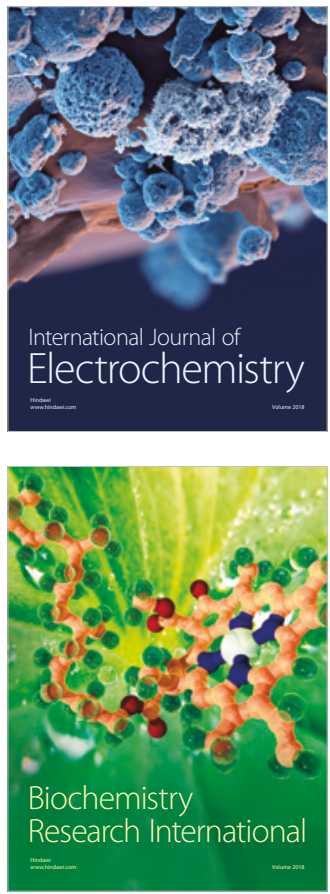